\title{
The Anti-proliferative Gene TIS21 Is Involved in Osteoclast Differentiation
}

\author{
Soo Woong Lee, Han Bok Kwak, Hong Chan Lee, Seung Ku Lee, \\ Hong-Hee Kim and Zang Hee Lee* \\ National Research Laboratory for Bone Metabolism, Research Center for Proteineous Materials, \\ and School of Dentistry, Chosun University, Gwangju
}

Received 2 September 2002, Accepted 1 October 2002

The remodeling process of bone is accompanied by complex changes in the expression levels of various genes. Several approaches have been employed to detect differentially-expressed genes in regard to osteoclast differentiation. In order to identify the genes that are involved in osteoclast differentiation, we used a cDNAarray-nylon membrane. Among 1,200 genes that showed a measurable signal, 19 genes were chosen for further study. Eleven genes were up-regulated; eight genes were downregulated. TIS21 was one of the up-regulated genes which were highly expressed in mature osteoclasts. To verify the cDNA microarray results, we carried out RT-PCR and real-time RT-PCR for the TIS21 gene. The TIS21 mRNA level was higher in differentiated-osteoclasts when compared to undifferentiated bone-marrow macrophages. Furthermore, the treatment with $1 \mu \mathrm{M}$ of a TIS21 antisense oligonucleotide reduced the formation of osteoclasts from the bone-marrow-precursor cells by $\sim 30 \%$. These results provide evidence for the potential role of TIS21 in the differentiation of osteoclasts.

Keywords: Antisense oligonucleotide, cDNA array, TIS21

\section{Introduction}

Bone is a dynamic-living tissue; its primary function is to provide an internal-support system in vertebrates. Osteoblasts that either form bone or resorb bones are present on bone surfaces. Osteoclasts are derived from the monocytemacrophage lineage of hematopoietic cells. They mediate the resorption process of bone modeling and remodeling in concert with other supporting cells, such as osteoblasts and stromal cells (Udagawa et al., 1990; Suda et al., 1992).

\footnotetext{
*To whom correspondence should be addressed.

Tel: 82-62-230-6872,7262; Fax: 82-62-227-6589

E-mail: jhblee@mail.chosun.ac.kr
}

According to studies with the op/op osteopetrotic mouse, which has a point mutation in the M-CSF gene, M-CSF has an important role in murine-osteoclast development (Felix et al., 1990; Tanaka et al., 1993). M-CSF may also regulate mature osteoclasts, including the prevention of osteoclast apoptosis and the enhancement of osteoclast motility (Fuller et al., 1993; Jimi et al., 1995). Recently, three important genes were identified and shown to be critical to osteoclast formation (Anderson et al., 1997; Simonet et al., 1997; Wong et al., 1997). First, RANKL is expressed on the surface of osteoblastic/stromal cells. RANKL is a receptor-activator of the nuclear-factor kappa B ligand, also called TRANCE (TNF-related activation-induced cytokine) or ODF (osteoclast differentiation factor) that is a member of the TNF family. It is essential for osteoclast differentiation. Second, RANK, which is a counter part of RANKL, is a new member of the TNFreceptor family. It is expressed in the progenitor and mature osteoclasts. Third, OPG (osteoprotegerin), which is a decoy receptor of the TNF-receptor family, may regulate the interaction between RANK and RANKL. It is, therefore, also called an osteoclastogenesis-inhibitory factor. Additionally, various cytokines, especially TNF- $\alpha$ and interleukin-1, are involved in osteoclast differentiation and survival (Jimi et al., 1999; Kobayashi et al., 2000). TNF- $\alpha$ and IL-1 are efficient osteoclastogenic factors in cells that have already received signals to commit osteoclastic differentiation. Also, TNF- $\alpha$ and IL-1 promoted the survival of mature osteoclasts by reducing apoptotic cell death through the PI 3-kinase/Akt and ERK signaling pathways (Lee et al., 2001; Lee et al., 2002). Besides these two cytokines, other cytokines are also involved in the regulation of osteoclastogenesis (Roodman, 1999).

The binding of RANKL to its receptor RANK provokes the recruitment of the signaling-adaptor molecules TRAFs (TNF receptor-associated factors) to the receptor complex, as well as the activation of the transcription factor, including NF- $\kappa \mathrm{B}$ (nuclear factor kappa B) (Lee et al., 2002). The activation of a nonreceptor-tyrosine kinase Src, a serine/threonine kinase Akt, and mitogen-activated kinases ERK, p38 and JNK, occur in response to RANK stimulation (Kim et al., 2001). Miyazaki 
et al. (Miyazaki et al., 2000) reported that the ERK activation is as essential in maintaining osteoclast survival as it is in the $\mathrm{NF}-\kappa \mathrm{B}$ pathway for the up-regulation of the bone-resorbing activity of osteoclasts.

The remodeling process of bone is accompanied by complex changes in the expression levels of various genes. Several approaches have been applied in order to detect the differentially-expressed genes in regard to osteoclast differentiation. These include subtractive hybridization (Petersen et al., 2000), differential display (Gori et al., 2001), the serial analysis of the gene expression (SAGE) (Seth et al., 2000), and, more recently, cDNA microarrays (Shi et al., 2001). The development of cDNA microarrays has emerged as a more rapid and efficient alternative to other genediscovery techniques. This technology allows the simultaneous-expression analysis of thousands of genes to be monitored in parallel. It also permits the identification of quantitative differences in both of the gene expressions of the known function, and novel genes and/or the expressedsequence tags (ESTs) of unknown functions. Few studies have used this approach to investigate gene-expression changes that are associated with the differentiation of bone cells (Raouf and Seth, 2002).

In this study, the genes that were differentially-expressed during osteoclastogenesis were examined by screening of the cDNA microarray. Experiments to identify the genes that are differentially-expressed during osteoclastogenesis led to the detection of TIS 21 as a gene that is up-regulated in differentiated-osteoclasts. The aim of the study was to provide evidence for the potential role of TIS21 in the differentiation of osteoclasts.

\section{Materials and Methods}

Cell culture Osteoclasts were generated from mouse-bonemarrow cells, as previously described (Zhang et al., 2001). Bonemarrow cells were obtained by flushing tibiae from 6-7 week-old ICR mice, suspended in an $\alpha$-minimum essential medium $(\alpha-$ MEM; Invitrogen Life Technologies, Carlsbad, USA) that contained $10 \%(\mathrm{v} / \mathrm{v})$ fetal bovine serum (FBS; Invitrogen), $100 \mathrm{U} /$ $\mathrm{ml}$ penicillin, $100 \mu \mathrm{g} / \mathrm{ml}$ streptomycin, and $10 \mathrm{ng} / \mathrm{ml}$ macrophagecolony-stimulating factor (M-CSF; Peprotech EC, London, England). The cells were cultured for $24 \mathrm{~h}$ at $37^{\circ} \mathrm{C}$ in a humidified atmosphere of $5 \% \mathrm{CO}_{2}$. The non-adherent cells were collected and separated on the Histopaque (Sigma, St. Louis, USA) gradient. The cells at the interface were harvested, resuspended at $1 \times 10^{6}$ cells $/ \mathrm{ml}$ in $\alpha$-MEM $/ 10 \%$ FBS, and cultured in the presence of $30 \mathrm{ng} / \mathrm{ml} \mathrm{M-}$ $\mathrm{CSF}$ and $50 \mathrm{ng} / \mathrm{ml}$ sRANKL (Peprotech EC) for 6 days.

The mouse macrophage/monocyte cell line RAW264 (RIKEN, Tsukuba Science City, Japan) was maintained in an $\alpha$-minimum essential medium ( $\alpha$-MEM; Gibco BRL, Gaithersburg, USA) with $5 \%$ FBS.

cDNA array assay A differential-gene-expression analysis was performed with mouse Atlas ${ }^{\mathrm{TM}}$ cDNA Expression Arrays (Clontech, Franklin Lakes, USA). Total RNA for the cDNA array was collected from bone-marrow-macrophage cells and fullydifferentiated-osteoclasts. The cDNA probe mixtures were synthesized by reverse-transcribing, each RNA population used a cDNA synthesis primer mix that was included in the kit and $[\alpha-$ $\left.{ }^{32} \mathrm{P}\right] \mathrm{dATP}$. Each radioactively-labeled-probe $\operatorname{mix}$ was then hybridized to separate Atlas Arrays. After a high-stringency wash, the hybridization pattern was analyzed by autoradiography and quantified by densitometry.

RT-PCR analysis Total RNA was prepared using TRI Reagent (Sigma, St. Louis, USA), following the manufacturers instructions. Two $\mu \mathrm{g}$ of total RNA were reverse-transcribed with SuperScriptII reverse transcriptase (Invitrogen), and $1 / 10$ of the reversetranscribed cDNA was amplified by PCR. For the TIS21 PCR amplification, the following primers were used: 5'-GGGTTC TGACTGGCTGGTGGG-3' and 5'-GGTGGAGAGAACGGGGA AGGG-3'. For the GAPDH PCR amplification, 5'-CAAGGCTGT GGGCAAGGTCA-3' and 5'-AGGTGGAAGAGTGGGAGTTGC TG-3' primers were used as sense and antisense primers, respectively. The expected sizes of the PCR products of TIS21 and GAPDH are $279 \mathrm{bp}$ and $242 \mathrm{bp}$, respectively. The PCR products were separated on $1.5-2.0 \%$ agarose gels and stained with ethidium bromide.

Real-time PCR The gene expression levels were also compared by real-time PCR analyses using the $\mathrm{SYBR}^{\circledR}$ Green dye and PE 5700 system (Perkin-Elmer Co., Bad Wildbad, Germany). The PCR reaction and data analysis were performed following the manufacturers guidelines. The sequences of the primer pairs were identical to those described previously. The primer concentrations were decided, based on optimization experiments. Next, $25 \mathrm{nM}$ and $50 \mathrm{nM}$ of each primer were used for the TIS2 1 and $\beta$-actin PCR reactions, respectively. One $\mu \mathrm{l}$ of the reverse-transcribed DNA, prepared as previously described, was used as the template, then $12.5 \mu \mathrm{l}$ of $2 \mathrm{X}$ SYBR Green PCR Master Mix (Perkin-Elmer Co.) was mixed with the template and primers. The total reaction volume was $25 \mu \mathrm{l}$. All of the PCR cycles were composed of one replication at $95^{\circ} \mathrm{C}$ for $10 \mathrm{~min}$, and 40 replications at $95^{\circ} \mathrm{C}$ for $15 \mathrm{~s}$ and at $60^{\circ} \mathrm{C}$ for $1 \mathrm{~min}$. Each sample was subjected to triplicate PCR reactions. The mean $\mathrm{C}_{\mathrm{T}}$ (threshold cycle; the cycle at which the increase in the signal that is associated with an exponential growth of PCR product is first detected) value of the differentiated-sample was compared to that of the undifferentiated-control sample using the mean $\mathrm{C}_{\mathrm{T}}$ value of $\beta$-actin as the internal control. The relative mRNA quantities of the differentiated-samples were calculated by the formula $2^{-\Delta} \Delta^{\mathrm{CT}}$, where $\Delta \mathrm{C}_{\mathrm{T}}$ is the difference between the mean $\mathrm{C}_{\mathrm{T}}$ value of TIS 21 and that of $\beta$-actin, $\Delta \Delta \mathrm{C}_{\mathrm{T}}$ is the difference between the $\Delta \mathrm{C}_{\mathrm{T}}$ values of the differentiated-samples and the mean $\Delta \mathrm{C}_{\mathrm{T}}$ value of the undifferentiated-control sample.

TRAP assays TRAP cytochemistry was performed using the Leukocyte Acid Phosphatase Assay Kit (Sigma), following the manufacturers procedure. The TRAP-stained cells were scored under a light microscope.

Antisense phosphorothioate-oligonucleotides experiments Bone marrow cells that were separated on the Histopaque gradient, as described previously, were cultured in the presence of $30 \mathrm{ng} / \mathrm{ml} \mathrm{M-}$ 
CSF and $50 \mathrm{ng} / \mathrm{ml}$ RANKL for $12 \mathrm{~h}$. The cells were then transfected with antisense oligonucleotides (5'-GGTTCTCTTCCC GTGGCTCAT-3', nucleotides 1142-1162 of GenBank M64292) or sense oligonucleotides (5'-ATGAGCCACGGGAAGAGAACC-3') that were synthesized with an automated DNA synthesizer (Atman Bioscience, Yongin, Korea) for TIS21 using Oligofectamine (Invitrogen) according to the manufacturers instructions. After supplementation with a medium that contained cytokines, the cells were cultured for three days. The medium was replaced, and the cells were further cultured for three days prior to the TRAP staining.

Statistical analysis All of the quantitative data were presented as mean \pm SD. Each experiment was performed in 3-5 replicates, and the results from one experiment that represents three independent experiments were shown. Statistical differences were analyzed by a Student's $t$-test.

\section{Results}

The cDNA array analysis of genes expressed during osteoclast differentiation In an effort to identify the genes that are associated with osteoclast differentiation, we employed the cDNA microarray technology. Osteoclasts were generated from mouse bone marrow-derived osteoclast precursors by culturing in the presence of osteoclastogenic cytokines. The differentiated-osteoclasts showed the typical multinuclear TRAP-positive characteristics (Fig. 1A, B). RNA was extracted from the precursor cells and differentiated-osteoclasts, then
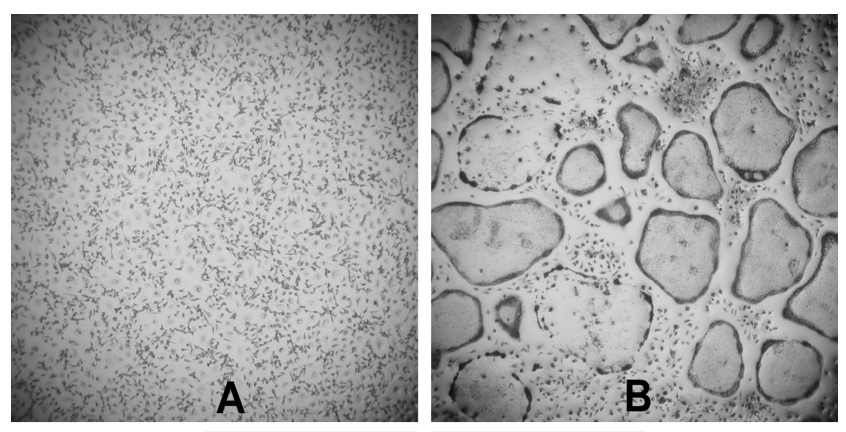

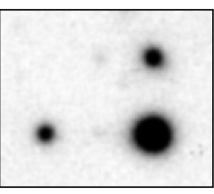

C

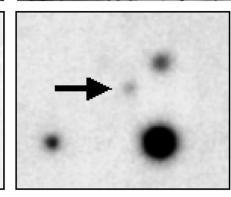

D
Fig. 1. TIS21 cDNA array profile of RNA from bone marrowderived precursor cells and differentiated-osteoclasts. The photographs of bone marrow-derived precursor cells (A) and differentiated-osteoclasts (B) with TRAP staining. The array membranes that were hybridized with RNA from precursor cells (C) and differentiated-osteoclast (D) are shown. The TIS21 gene is indicated by an arrow. The three strong dots are internal standard cDNAs of the array membrane. applied to cDNA microarray membranes and the gene expression profile was compared before and after the osteoclast differentiation. Among the 1,200 genes in this microarray membrane, 11 genes were up-regulated, and 8 genes were down-regulated by more than two-fold. TIS21 was one of the up-regulated genes during differentiation (Fig. 1C, D).

RT-PCR and real-time RT-PCR To verify the results that were obtained by the CDNA microarray analysis, we carried out RT-PCR and real-time RT-PCR for the TIS21 gene. TIS21 was highly expressed in differentiated-osteoclasts when compared to the undifferentiated bone-marrow macrophages (Fig. 2). GAPDH, a housekeeping gene, served as the internal control. We also confirmed this result using real-time RT-PCR technique. Both in the bone marrow macrophage-derived osteoclasts and Raw264 cell-line-derived osteoclast-like cells, the expression level of the TIS 21 gene was higher in the differentiated cells (Fig. 3).

Effects of an antisense oligonucleotide on osteoclast differentiation We next examined whether or not TIS21 is involved in the osteoclast differentiation. An antisense oligonucleotide for the TIS21 gene was added to the osteoclastogenic culture of the bone marrow cells. As shown in Figure 4 , the treatment with $1 \mu \mathrm{M}$ of the antisense oligonucleotide reduced the number of TRAP-positive cells by $\sim 30 \%$. Treatment with the sense oligonucleotide had no effect on the TRAP staining of osteoclast. This result indicates that TIS21 may contribute to osteoclast differentiation.

\section{Discussion}

Identification of the proteins that are associated with normal growth and differentiation during osteoclastogenesis can help to elucidate the molecular mechanisms that underlie bone

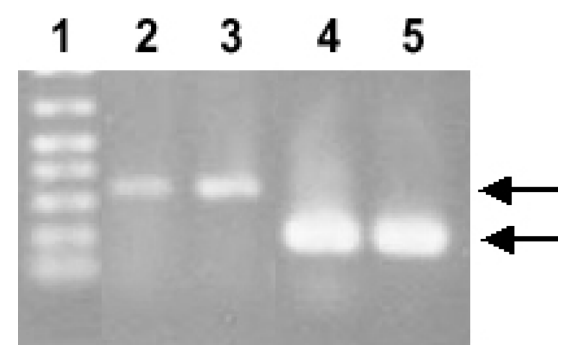

Fig. 2. Semiquantitative RT-PCR of TIS21 using RNAs from cells during osteoclast differentiation. The histopaque-purified nonadherent mouse bone marrow cells were prepared, as described in Materials and Methods. Total RNA was extracted from these cells (lane 2) and from the culture of these cells in the presence of $10 \mathrm{ng} /$ $\mathrm{ml} \mathrm{M-CSF}$ and $30 \mathrm{ng} / \mathrm{ml}$ RANKL for 6 days (lane 3). The RNA was reverse-transcribed and PCR amplified with TIS21 (lanes 2 and 3) or GAPDH (lanes 4 and 5) primers. The PCR products were subjected to agarose gel electrophoresis. The marker DNA is indicated in lane 1. 

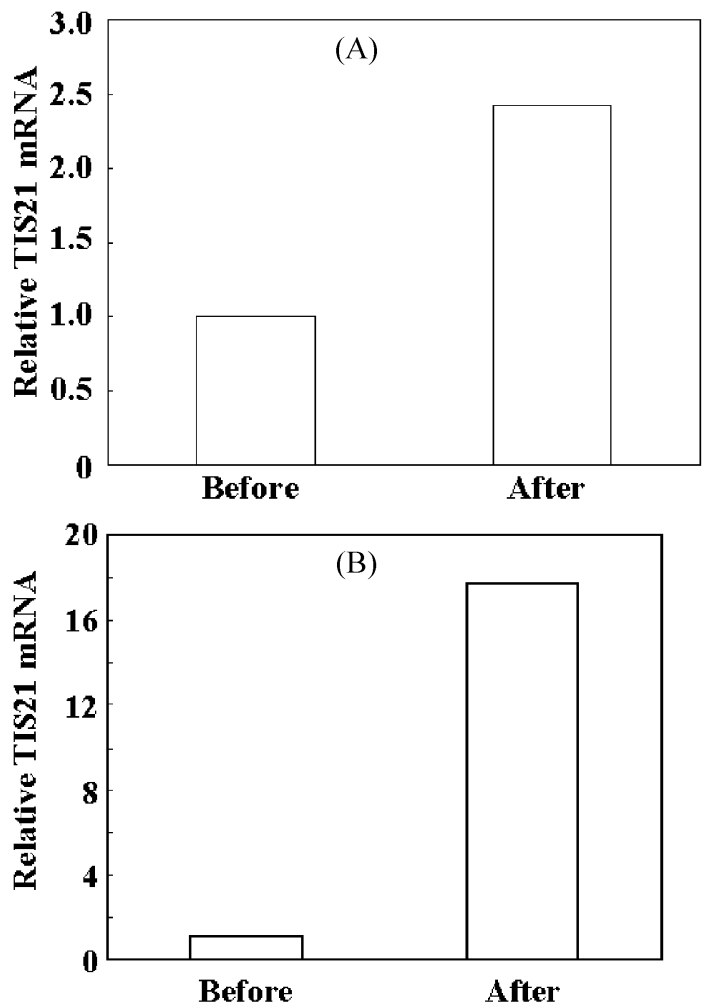

Fig. 3. Real-time PCR of TIS21 using RNAs from bone marrow cells and RAW264 cells. Total RNA was extracted from cells, undifferentiated (before) and differentiated (after) bone marrowderived macrophages (A) and RAW264 cells (B). RNA was reverse-transcribed and the level of TIS 21 mRNA was assessed by real-time PCR analyses using $\beta$-actin as an internal control.

modeling and remodeling. Recently, the cDNA microarray technique was successfully used in identifying the differentiation stage-specific gene expression in human mesenchymal stem cells (Doi et al., 2002), human dental pulp stem cells (Shi et al., 2001), and murine osteoblasts (Raouf and Seth, 2002). It is estimated that 5,000 to 10,000 different genes are expressed by a differentiated cell, such as osteoclast (Cappellen et al., 2002). Most of these genes are involved in 'housekeeping' activities, and are found in many cell types. However, a subset of about 100 to 200 genes may have either a unique or selective expression in osteoclasts, and hence define the phenotype of these cells. In this study, we utilized a cDNA array nylon membrane to discover the new osteoclastdifferentiation-associated genes. Among the 1,200 genes that showed a measurable signal, 19 genes were chosen for further study. Eleven genes were up-regulated; eight genes were downregulated. TIS21 is one of the up-regulated genes (Fig. 1).

The TIS21 (mouse form), PC3 (rat form), or BTG2 (human form) genes were originally described as immediate early genes that are induced by the tumor-promoter-tetradecanoylphorbol acetate in the mouse 3T3 cell line (Fletcher et al., 1991). The TIS21 expression is critical for regulation of normal cell growth. TIS21 induces G1 arrest in the cell cycle

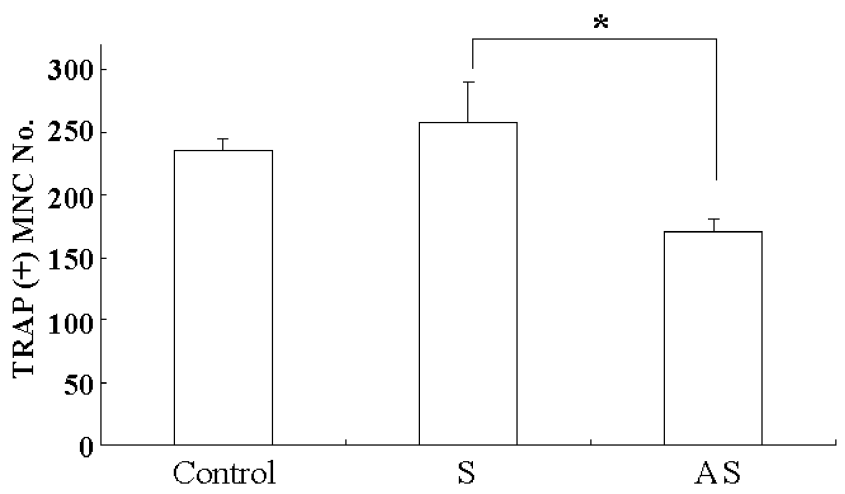

Fig. 4. Effects of an antisense TIS 21 oligonucleotide on the generation of TRAP-positive osteoclasts from bone marrow cells. The non-adherent bone marrow cells were transfected with $1 \mu \mathrm{M}$ of TIS21 sense (S) and antisense (AS) oligonucleotides, as described in Materials and Methods. The control transfection with no oligonucleotide (Control) was also included. The cells were then subjected to TRAP-staining, and the TRAP-positive cells were counted. *, $\mathrm{p}<0.01$ versus sense oligonucleotide.

by inactivating $\mathrm{pRb}$ (retinoblastoma protein) or p53 (Tirone, 2001). Growth arrest of the committed cells is a common feature that occurs during cell differentiation.

It has been reported that RANKL induced the dephosphorylation of $\mathrm{pRb}$, and thereafter resulted in a delayed S-phase progression in RAW264 cells (Meiyanto et al., 2001). This suggests that RANKL exerts the anti-proliferative effects through $\mathrm{Rb}$ during osteoclast differentiation. The mRNA expression of TIS21 was increased as osteoclasts differentiated (Fig. 2, 3). Considering these facts, it is plausible that RANKL induces TIS21 in order to stop the proliferation of committed-osteoclast-precursor cells as a part of its differentiation-driving programs.

Antisense oligonucleotides were widely used in order to obtain clues for the gene function. This approach has been particularly useful for studies on osteoclast differentiation and osteoclastic-bone resorption, as osteoclasts have a phagocytic function and are relatively efficient in taking-up oligonucleotides. Ishikawa (Ishikawa et al., 2001) reported that cathepsin K might play an important role in bone resorption, as well as in the differentiation of osteoclasts. Suhr (Suhr et al., 2001) reported that the osteoclastic-transmembrane-proteintyrosine-phosphatase-antisense-oligonucleotide treatment to isolated osteoclasts decreased the basal or stimulated bone resorption activity. Also, the antisense oligonucleotide of the p91 and p47 subunits in the IFN-gamma receptor abrogated the increased osteoclastic superoxide production that is stimulated by IFN-gamma (Yang et al., 2002). In this study, we found that a phosphorothioated-antisense oligonucleotide that corresponds to a unique sequence around the initiation site of the TIS 21 gene was effective in blocking the differentiation into TRAPpositive osteoclasts (Fig. 4). This result suggested that TIS21 might play important roles in the differentiation of osteoclasts 
by inducing the cell-cycle arrest of committed-osteoclast precursors.

In summary, we found that TIS21 is up-regulated in differentiated-osteoclasts by the cDNA array technique, and plays a role in the osteoclast-differentiation process. The application of genomics approaches is expected to yield the identification of a large number of genes and gene families that are involved in the process of bone formation and bone remodeling. The identification and characterization of these genes will provide significant insights into the pathogenesis of numerous human bone diseases. TIS 21 is one of the candidate molecules that may be responsible for osteoclast differentiation. It may also be useful as a novel biochemical marker for the diagnosis of osteolytic diseases, or as a target for the development of therapeutic agents that interfere with pathological bone resorption.

Acknowledgments This study was supported by a grant from the Korea Health 21 R\&D Project, Ministry of Health and Welfare, Republic of Korea (02-PJ1-PG10-20908-0006).

\section{References}

Anderson, D. M., Maraskovsky, E., Billingsley, W. L., Dougall, W. C., Tometsko, M. E., Roux, E. R., Teepe, M. C., DuBose, R. F., Cosman, D. and Galibert, L. (1997) A homologue of the TNF receptor and its ligand enhance T-cell growth and dendritic-cell function. Nature 390, 175-179.

Cappellen, D., Luong-Nguyen, N., H., Bongiovanni, S., Grenet, O., Wanke, C. and Susa, M. (2002) Transcriptional program of mouse osteoclast differentiation governed by the macrophage colony-stimulating factor and the ligand for the receptor activator of NFkappa B. J. Biol. Chem. 277, 21971-21982.

Doi, M., Nagano, A. and Nakamura, Y. (2002) Genome-wide screening by cDNA microarray of genes associated with matrix mineralization by human mesenchymal stem cells in vitro. Biochem. Biophys. Res. Commun. 290, 381-390.

Felix, R., Cecchini, M. G., Hofstetter, W., Elford, P. R., Stutzer, A. and Fleisch, H. (1990) Impairment of macrophage colonystimulating factor production and lack of resident bone marrow macrophages in the osteopetrotic op/op mouse. J. Bone Miner. Res. 5, 781-789.

Fletcher, B. S., Lim, R. W., Varnum, B. C., Kujubu, D. A., Koski, R. A. and Herschman, H. R. (1991) Structure and expression of TIS21, a primary response gene induced by growth factors and tumor promoters. J. Biol. Chem. 266, 14511-14518.

Fuller, K., Owens, J. M., Jagger, C. J., Wilson, A., Moss, R. and Chambers, T. J. (1993) Macrophage colony-stimulating factor stimulates survival and chemotactic behavior in isolated osteoclasts. J. Exp. Med. 178, 1733-1744.

Gori, F., Divieti, P. and Demay, M. B. (2001) Cloning and characterization of a novel WD-40 repeat protein that dramatically accelerates osteoblastic differentiation. J. Biol. Chem. 276, 46515-46522.

Ishikawa, T., Kamiyama, M., Tani-Ishii, N., Suzuki, H., Ichikawa, Y., Hamaguchi, Y., Momiyama, N. and Shimada, H. (2001) Inhibition of osteoclast differentiation and bone resorption by cathepsin K antisense oligonucleotides. Mol. Carcinog. 32, 84-
91.

Jimi, E., Nakamura, I., Duong, L. T., Ikebe, T., Takahashi, N., Rodan, G. A. and Suda, T. (1999) Interleukin 1 induces multinucleation and bone-resorbing activity of osteoclasts in the absence of osteoblasts/stromal cells. Exp. Cell Res. 247, 84-93.

Jimi, E., Shuto, T. and Koga, T. (1995) Macrophage colonystimulating factor and interleukin-1 alpha maintain the survival of osteoclast-like cells. Endocrinology 136, 808-811.

Kim, H. H., Kim, H. M., Kwack, K., Kim, S. W. and Lee, Z. H. (2001) Osteoclast Differentiation Factor Engages the PI 3kinase, p38, and ERK pathways for Avian Osteoclast Differentiation. J. Biochem. Mol. Biol. 34, 421-427.

Kobayashi, K., Takahashi, N., Jimi, E., Udagawa, N., Takami, M., Kotake, S., Nakagawa, N., Kinosaki, M., Yamaguchi, K., Shima, N., Yasuda, H., Morinaga, T., Higashio, K., Martin, T. J. and Suda, T. (2000) Tumor necrosis factor alpha stimulates osteoclast differentiation by a mechanism independent of the ODF/RANKL-RANK interaction. J. Exp. Med. 191, 275-286.

Lee, S. E., Chung, W. J., Kwak, H. B., Chung, C. H., Kwack, K. B., Lee, Z. H. and Kim, H. H. (2001) Tumor necrosis factoralpha supports the survival of osteoclasts through the activation of Akt and ERK. J. Biol. Chem. 276, 49343-49349.

Lee, S. W., Han, S. I., Kim, H. H. and Lee, Z. H. (2002) TAK1dependent Activation of AP-1 and c-Jun N-terminal Kinase by Receptor Activator of NF-אB. J. Biochem. Mol. Biol. 35, 371376.

Lee, Z. H., Lee, S. E., Kim, C. W., Lee, S. H., Kim, S. W., Kwack, K., Walsh, K. and Kim, H. H. (2002) IL-1alpha stimulation of osteoclast survival through the PI 3-kinase/Akt and ERK pathways. J. Biochem. (Tokyo) 131, 161-166.

Meiyanto, E., Hoshijima, M., Ogawa, T., Ishida, N. and Takeya, T. (2001) Osteoclast differentiation factor modulates cell cycle machinery and causes a delay in $\mathrm{s}$ phase progression in RAW264 cells. Biochem. Biophys. Res. Commun. 282, 278283.

Miyazaki, T., Katagiri, H., Kanegae, Y., Takayanagi, H., Sawada, Y., Yamamoto, A., Pando, M. P., Asano, T., Verma, I. M., Oda, H., Nakamura, K. and Tanaka, S. (2000) Reciprocal role of ERK and NF-kappaB pathways in survival and activation of osteoclasts. J. Cell Biol. 148, 333-342.

Petersen, D. N., Tkalcevic, G. T., Mansolf, A. L., RiveraGonzalez, R. and Brown, T. A. (2000) Identification of osteoblast/osteocyte factor 45 (OF45), a bone-specific cDNA encoding an RGD-containing protein that is highly expressed in osteoblasts and osteocytes. J. Biol. Chem. 275, 36172-36180.

Raouf, A. and Seth, A. (2002) Discovery of osteoblast-associated genes using cDNA microarrays. Bone 30, 463-471.

Roodman, G. D. (1999) Cell biology of the osteoclast. Exp. Hematol. 27, 1229-1241.

Seth, A., Lee, B. K., Qi, S. and Vary, C. P. (2000) Coordinate expression of novel genes during osteoblast differentiation. $J$. Bone Miner. Res. 15, 1683-1696.

Shi, S., Robey, P. G. and Gronthos, S. (2001) Comparison of human dental pulp and bone marrow stromal stem cells by cDNA microarray analysis. Bone 29, 532-539.

Simonet, W. S., Lacey, D. L., Dunstan, C. R., Kelley, M., Chang, M. S., Luthy, R., Nguyen, H. Q., Wooden, S., Bennett, L., Boone, T., Shimamoto, G., DeRose, M., Elliott, R., Colombero, A., Tan, H. L., Trail, G., Sullivan, J., Davy, E., Bucay, N., Renshaw-Gegg, L., Hughes, T. M., Hill, D., Pattison, W., 
Campbell, P. S., Sander, G., Van, J., Tarpley, P., Derby, R. Lee. and W, J. Boyle. (1997) Osteoprotegerin: a novel secreted protein involved in the regulation of bone density. Cell 89, 309319.

Suda, T., Takahashi, N. and Martin, T. J. (1992) Modulation of osteoclast differentiation. Endocrine Rev. 13, 66-80.

Suhr, S. M., Pamula, S., Baylink, D. J. and Lau, K. H. (2001) Antisense oligodeoxynucleotide evidence that a unique osteoclastic protein-tyrosine phosphatase is essential for osteoclastic resorption. J. Bone Miner. Res. 16, 1795-1803.

Tanaka, S., Takahashi, N., Udagawa, N., Tamura, T., Akatsu, T., Stanley, E. R., Kurokawa, T. and Suda, T. (1993) Macrophage colony-stimulating factor is indispensable for both proliferation and differentiation of osteoclast progenitors. J. Clin. Invest. 91, 257-263.

Tirone, F. (2001) The gene PC3(TIS21/BTG2), prototype member of the PC3/BTG/TOB family: regulator in control of cell growth, differentiation, and DNA repair? J. Cell. Physiol. 187, 155-165.

Udagawa, N., Takahashi, N., Akatsu, T., Tanaka, H., Sasaki, T.,
Nishihara, T., Koga, T., Martin, T. J. and Suda, T. (1990) Origin of osteoclasts: mature monocytes and macrophages are capable of differentiating into osteoclasts under a suitable microenvironment prepared by bone marrow-derived stromal cells. Proc. Natl. Acad. Sci. USA 87, 7260-7264.

Wong, B. R., Rho, J., Arron, J., Robinson, E., Orlinick, J., Chao, M., Kalachikov, S., Cayani, E., Bartlett, F. S. $3^{\text {rd }}$., Frankel, W. N., Lee, S. Y. and Choi, Y. (1997) TRANCE is a novel ligand of the tumor necrosis factor receptor family that activates c-Jun N-terminal kinase in T cells. J. Biol. Chem. 72, 25190-25194.

Yang, S., Madyastha, P., Ries, W. and Key, L. L. (2002) Characterization of interferon gamma receptors on osteoclasts: effect of interferon gamma on osteoclastic superoxide generation. J. Cell Biochem. 84, 645-654.

Zhang, Y. H., Heulsmann, A., Tondravi, M. M., Mukherjee, A. and Abu-Amer, Y. (2001) Tumor necrosis factor-alpha (TNF) stimulates RANKL-induced osteoclastogenesis via coupling of TNF type 1 receptor and RANK signaling pathways. J. Biol. Chem. 276, 563-568. 